\title{
Evidence for Direct Estrogen Regulation of the Human Gonadotropin-releasing Hormone Gene
}

\author{
S. Radovick, ${ }^{\star}$ C. M. Ticknor, ${ }^{\star}$ Y. Nakayama, ${ }^{\text {A. C. Notides," A. Rahman, }}$ \\ B. D. Weintraub, ${ }^{\ddagger}$ G. B. Cutler, Jr.," and F. E. Wondisford* \\ *Divisions of Pediatric and Adult Endocrinology, University Hospitals of Cleveland and Case Western Reserve School of Medicine, \\ Cleveland, Ohio 44106; ' National Institute of Diabetes and Digestive and Kidney Disease, Bethesda, Maryland 20892; \\ ${ }^{\S}$ University of Rochester School of Medicine, Rochester, New York 14642; and "National Institute \\ of Child Health and Human Development, Bethesda, Maryland 20892
}

\section{Abstract}

This study is an attempt to determine whether estrogen could directly regulate human gonadotropin-releasing hormone (GnRH) gene expression. Human GnRH expression vectors were constructed by fusing various $5^{\prime}$ flanking regions of the human GnRH gene upstream of the luciferase reporter gene (LUC) or the thymidine kinase promoter linked to the chloramphenicol acetyltransferase reporter gene (CAT). These constructs were transiently transfected into a human choriocarcinoma cell line (JEG-3) and LUC or CAT activity was measured after either no treatment or treatment with various concentrations of estradiol. A stimulatory estrogen response element (ERE) was localized to a 32-bp region between -547 and -516 bp.

To determine whether estrogen receptor bound to this region of the gene, we performed DNase I footprinting using purified calf uterine estrogen receptor. DNase I footprinting demonstrates a strong footprint between -567 and -514 bp of the human GnRH gene. In addition, an avidin-biotin complex DNA-binding assay demonstrated that a biotinylated DNA fragment containing -541 to -517 bp of the human GnRH gene bound ${ }^{35} \mathrm{~S}-$ labeled estrogen receptor as well as a biotinylated DNA fragment containing the xenopus vitellogenin ERE. On the other hand, the negative control biotinylated DNA fragment derived from adenovirus 5 bound insignificant amounts of ${ }^{35}$ S-labeled estrogen receptor. Both the GnRH ERE and vitellogenin ERE bound ${ }^{35} \mathrm{~S}$-labeled estrogen receptor with high affinity $(\sim 1 \mathrm{nM})$.

These data indicate that the human GnRH gene contains an ERE sufficient to mediate a stimulatory response to estrogen in heterologous cells. Based upon these data we hypothesize that the human GnRH gene might also be directly regulated by estrogen in the hypothalamus, and that this regulation may explain the GnRH hypersecretion observed at the time of the preovulatory luteinizing hormone (LH) surge. (J. Clin. Invest. 1991. 88:1649-1655.) Key words: GnRH • estrogen • gene regulation • hypothalamus

Address correspondence to Dr. Sally Radovick, Case Western Reserve University School of Medicine, W147, 2119 Abington Road, Cleveland, $\mathrm{OH} 44106$.

Received for publication 23 January 1991 and in revised form 24 May 1991.

J. Clin. Invest.

(c) The American Society for Clinical Investigation, Inc. $0021-9738 / 91 / 11 / 1649 / 07 \quad \$ 2.00$

Volume 88, November 1991, 1649-1655

\section{Introduction}

Gonadotropin-releasing hormone $(\mathrm{GnRH})^{1}$ is a hypothalamic decapeptide that is key to controlling mammalian reproduction. GnRH is synthesized as a preprohormone in hypothalamic neurosecretory cells and stimulates the release of luteinizing hormone (LH) and follicle-stimulating hormone (FSH) from the anterior pituitary. GnRH immunoreactivity is present in the median emminence and arcuate nucleus of the medial basal hypothalamus and in the organum vasculosum of the lamina terminalis and suprachiasmatic nuclei. GnRH neurons are also found in the cerebral cortex, limbic system, and olfactory bulbs. In a recent study, Wray et al. (1) found GnRH mRNA in approximately 800 neurons in the rat brain using in situ hybridization techniques.

GnRH release occurs episodically from the hypothalamus, and the frequency and amplitude of $\mathrm{GnRH}$ release determine the pattern of gonadotropin secretion $(2,3)$. Estrogen is a major hormonal regulator of $\mathrm{GnRH}$ release from the hypothalamus. Several physiological studies in animals and man suggest that estrogen regulates GnRH expression. For example, castrated rhesus monkeys demonstrate an increased amplitude of GnRH release into their portal circulation (4). Additionally, Gross et al. (5) showed that castration resulted in an increased level of GnRH secretion from the median emminence. GnRH levels were reduced to control levels by gonadal steroid hormone replacement. However, Rudenstein et al. (6) found that hypothalamic $\mathrm{GnRH}$ release from castrated rats was significantly lower than that from control animals. In this study, gonadal steroid replacement increased GnRH release to near control levels. In humans, Reame et al. (7) suggested that the late follicular phase increase in estradiol may increase GnRH pulse frequency. Apparent contradictions in these studies may be explained by different effects of gonadal steroids on hypothalamic GnRH release, depending upon the duration and dosage of hormone exposure or perhaps upon the method used to measure GnRH secretion.

To study more directly the effect of estrogen on GnRH expression, several investigators have used in situ hybridization to the GnRH mRNA. Pfaff (8) reported that estradiol given over $7 \mathrm{~d}$ increased GnRH mRNA in ovariectomized rats. Moreover, Rothfield et al. (9) noted that male rats castrated for 2 wk

1. Abbreviations used in this paper: AD5, adenovirus 5; CAT, chloramphenicol acetyltransferace reporter gene; ER, estrogen receptor; ERE, estrogen response element; GnRH, human gonadotropin-releasing hormone; JEG-3, human choriocarcinoma cell line; LUC, luciferase reporter gene; VIT.ERE, ERE from the xenopus vitellogenin gene. 
had a significant decrease in GnRH mRNA compared with control animals. Similarly, Roberts (10), Rothfeld (11), and most recently Park (12) reported stimulatory effects of estradiol on GnRH gene expression. However, Zoeller et al. (13) found that $2 \mathrm{~d}$ of estradiol treatment to ovariectomized rats signifcantly inhibited GnRH mRNA expression and Wray (14) similarly found inhibition of GnRH gene expression by estradiol in select GnRH-neuronal populations. Lastly, Toranzo et al. (15) showed that estradiol replacement decreased proGnRH mRNA accumulation in the brain of ovariectomized rats. Apparent contradictions among these studies point out the diffculties in studying GnRH neuronal regulation in vivo where complex neuronal pathways, different populations of $\mathrm{GnRH}$ neurons, differences in sensitivity of various techniques, and the physiologic time points studied may be major confounding variables. However, it is clear from these studies that estrogen regulates GnRH mRNA expression.

Since estrogen interacts with a specific nuclear receptor that binds to specific DNA sequences, termed EREs, it is clear that estrogen-responsive cells must contain estrogen receptors. Receptors for estrogen are present in areas which largely overlap those of GnRH-containing neurons (3). However, it is unclear if the GnRH neuron itself contains estrogen receptors. For instance, Shivers et al. (16) reported that only $0.2 \%$ of GnRH neurons concentrate a measurable amount of radiolabeled estradiol. Moreover, Watson et al. (17) reported that only a few GnRH neurons were immunopositive for the estrogen receptor. These studies, though, lack the sensitivity needed to detect a low abundance of estrogen receptors sufficient to mediate a hormonal response. For example, Komm et al. (18) and Eriksen et al. (19) reported that bone tissue contains a low number of estrogen receptors, previously undetectable by standard methods, sufficient to mediate an estrogen response. Moreover, it is also plausible that only certain populations of $\mathrm{GnRH}$ neurons contain sufficient estrogen receptors and are directly responsive to estrogen. Thus, whether estrogen affects GnRH expression directly or indirectly via other neuronal circuits remains to be determined.

In the present study, we sought to determine whether estrogen could directly regulate the expression of the human GnRH gene in transfected cell cultures. Because a GnRH-secreting neuronal cell line was not available at the time of these studies, they were performed in a human placental cell line (JEG-3). We localized an ERE to between -547 and -516 bp of the human GnRH 5' flanking region. DNase I footprinting and the avidin-biotin DNA-binding assay demonstrate that the human estrogen receptor binds with high affinity to human GnRH sequences from -567 to $-514 \mathrm{bp}$ and -541 to $-517 \mathrm{bp}$, respectively. These data demonstrate, for the first time, that estrogen can directly regulate $\mathrm{GnRH}$ gene expression, and suggest that GnRH hypersecretion at the time of the preovulatory LH surge might be explained by a direct stimulatory effect of estrogen on human GnRH gene expression in the hypothalamus.

\section{Methods}

Materials. Restriction and modifying enzymes were obtained from Bethesda Research Laboratories (Gaithersburg, MD). Oligonucleotides were synthesized on a gene assembler. Thermus aquaticus (Pharmacia LKB, Inc., Piscataway, NJ). (Taq) polymerase was purchased from Perkin-Elmer-Cetus Corp. (Norwalk, CT), and all PCR reactions were carried out in a thermal cycler (Perkin-Elmer-Cetus). Cell culture re- agents were purchased from Advanced Biotechnologies, Inc. (Columbia, MD). Acetyl CoA was purchased from Calbiochem-Behring Corp. (San Diego, CA). Luciferin (sodium salt) was obtained from Sigma Chemical Co. (St. Louis, MO).

Plasmid constructions. All plasmid constructs were made using standard methods (20). The pTKCAT constructs were made by ligating various human GnRH genomic fragments into the BamHI site upstream of the herpes virus thymidine kinase promoter $(-199$ to +12$)$ in pTKCAT (21). The $-1131 /-546,-551 /+5$, and $-551 /-459$ bp DNA fragments were obtained using Hind III and BamHI, BamHI and Sca I, and BamHI and Acc I, respectively and were inserted into the BamHI of pTKCAT using BamHI linkers. Synthetic complementary oligonucleotides containing either the palindromic vitellogenin ERE, 5'CTCAGGTCACAGTGACCTGAG-3', or one or two copies of the human GnRH. ERE from -547 to -516 bp were synthesized with Kpn I and BamHI ends and inserted upstream of the TK promoter in pTKCAT.

For the construct $\mathrm{pGnRH} .2 \mathrm{E}, \mathrm{a}-1131$ to $+829 \mathrm{bp}$ gene fragment was obtained using Hind III and Pst I and ligated to $a+830$ to +1073 bp fragment obtained from the polymerase chain reaction (PCR) with a 115 ' primer and a $2 \mathrm{E} 3$ ' primer. The 5' primer was synthesized with a Pst I restriction endonuclease site and the $\mathbf{3}^{\prime}$ primer with a Hind III site. The 2E3' primer has a stop codon (TAA) at the end of the second exon in the appropriate reading frame. For the construct pGnRH.3E, a -1131 to +2429 genomic fragment (Hind III and Bgl II site) was obtained and ligated to a +2430 to +2684 PCR fragment (2I5' primer with a Bgl II site and a 3E3' primer with a Hind III site). The 3E3' primer had a stop codon (TAA) at the end of the third exon in the appropriate reading frame. A -82 to +1073 PCR fragment was synthesized using a -82 primer and a $2 E 3^{\prime}$ primer, both with Hind III sites. All fragments were ligated into the Hind III site of pSVOAL $\Delta 5^{\prime}$ (obtained from S. Subramani, University of California, San Diego, CA [22]) and each construct was confirmed using multiple restriction enzyme digests and dideoxynucleotide DNA sequencing (23). pRSVL (obtained from S. Subramani [22]) contains the Rous sarcoma virus promoter upstream of the luciferase reporter and was used as a control construct in some experiments.

Transfection and reporter assays. JEG-3 cells were maintained in DME supplemented with $4 \%$ fetal bovine serum, and replaced with fresh media $4 \mathrm{~h}$ before transfection. Transfections were carried out in triplicate using $20 \mu \mathrm{g}$ of test plasmid for each plate and the calciumphosphate precipitation method. In some experiments, $2 \mu \mathrm{g}$ of pRSVCAT was cotransfected to correct for transfection efficiency. After 16-18 h of incubation with precipitate, cells were shocked for 2 min with $15 \%$ glycerol in Hepes saline and washed with serum-free medium. The cells were then incubated in DME containing 4\% charcoal-stripped fetal bovine serum with or without estradiol at the indicated concentration. Cells were harvested $48 \mathrm{~h}$ after transfection and CAT or LUC activity was measured as described previously $(22,24)$. Protein content of the cellular extract was determined by the Bradford method (Protein assay Kit, Bio-Rad Laboratories, Richmond, CA).

Cell cultures transfected with the promoterless vector alone, pSVOAL $\Delta 5^{\prime}$, displayed LUC activity similar to mock-transfected cells. pSVOAL $\Delta 5^{\prime}$ contains two polyadenylation signals upstream from the Hind III cloning site to prevent read-through transcription from cryptic promoter sites in pBR322. Thus, this vector has low background activity in this assay system.

DNAse I footprinting. DNAse I footprinting was performed utilizing a human GnRH-DNA-PCR fragment from -611 to $-82 \mathrm{bp}$. This fragment contained a $5^{\prime}$ Hind III site that was labeled using Taq polymerase, dGTP, dCTP, dTTP, and $\left[\alpha^{-32}\right.$ P]ATP. Purified calf uterus estrogen receptor was prepared as described (25). DNA-binding reactions were performed in $50 \mu \mathrm{l}$ of a buffer containing $50 \mathrm{mM} \mathrm{KCl}, 10 \%$ glycerol, $20 \mathrm{mM}$ Tris pH 8.0, $1 \mathrm{mM}$ DTT, $1 \mathrm{mM} \mathrm{MgCl}_{2}, 1 \mathrm{mM}$ EDTA, 100 $\mathrm{nM}$ estradiol, $100 \mu \mathrm{g} / \mathrm{ml} \mathrm{BSA}, 4 \mu \mathrm{g}$ of poly dI-dC, and $11 \mathrm{mM} \beta$-mercaptoethanol for $30 \mathrm{~min}$ at $25^{\circ} \mathrm{C}$. Binding reaction contained between 0 and $17 \mathrm{nM}$ of purified estrogen receptor. At the highest estrogen receptor concentration $(17 \mathrm{nM})$, receptor constituted only $1 \%$ of the 
total protein in the binding reaction due to the addition of BSA to each reaction. DNase I $(0.6 \mu \mathrm{g})$ was used for partial digestion of the radiolabeled template $\left(2 \mathrm{~min}\right.$ at $\left.25^{\circ} \mathrm{C}\right)$; and the reaction was terminated by adding $100 \mu \mathrm{l}$ of a solution containing $50 \mathrm{mM}$ EDTA, $1 \%$ SDS, and 20 $\mu \mathrm{g}$ of yeast tRNA. The digested products were extracted with phenol and chloroform, precipitated with ethanol, and resolved on an $8 \%$ denaturing polyacrylamide gel.

Avidin-biotin complex DNA-binding assay. To test whether ERE of human GnRH would bind ${ }^{35} \mathrm{~S}$-labeled human ER, the avidin-biotin complex DNA-binding assay (ABCD assay) was employed. Doublestranded oligonucleotides from the long terminal repeat of adenovirus 5 (5'-AGGGAAGGAAGGTGTACACAGGAAGTGACAATTTTCGCA-3' and 5'-GAAGAGAGAATGCGAAAATTGTCACTTCCTGTGTACACC-3'), the xenopus vitellogenin ERE (5'-AGGGAAGGAATCAGGTCACTGTGACCTGA-3' and 5'-GAAGAGAGAATCAGGTCACAGTGACCTGA-3'), and the human GnRH gene (-551 to $-512 \mathrm{bp}, 5$-AGGGAAGGAAGGATCCTACATGGACTTGGTATATAGTGTCACTTACTTGT- ${ }^{\prime}$ and 5'-GAAGAGAGAA ACAAGTAAGTGACACTATATACCAAGTCCATGTAGGATCC$3^{\prime}$ ) were synthesized with identical 5 ' overhangs (underlined) and filled in with biotin-11 dUTP and dCTP using Taq DNA polymerase. Smaller biotinylated DNA fragments of the human GnRH gene, including and surrounding the ERE, were also synthesized with the above 5 ' overhangs. Each DNA fragment was designed to incorporate 11 biotin 11-dUTP residues. Radiolabeled ${ }^{35}$ S $]$ methionine human ER was prepared using an in vitro transcription-translation system. Briefly, the human ER (gift of P. Chambon) was cloned into the pGEM4Z vector and in vitro human ER mRNA was synthesized using SP6 polymerase. This mRNA $(1 \mu \mathrm{g})$ was translated in a rabbit reticulocyte lysate system containing $\left[{ }^{35} \mathrm{~S}\right]$ methionine (New England Nuclear, Boston, MA). Binding reactions were performed as described previously (20) except that $0.1 \%$ BSA was added to the binding buffer. Each binding reaction contained various concentrations of the respective biotinylated DNA fragment $(20 \mathrm{nM})$ and $1 \times 10^{-4} \mathrm{cpm}$ of ${ }^{35} \mathrm{~S}$-labeled human ER as determined by TCA precipitation. The concentration of biotinylated DNA fragments was quantitated using a DNA fluorometric assay (Mini Fluorometer; Hoefer Scientific, San Francisco, CA).

\section{Results}

DNA transfection studies to localize estrogen-responsive regions in the human GnRH gene. To determine whether the human GnRH gene contains DNA sequences that may mediate estrogen responsiveness, CAT expression vectors using the native promoter were initially constructed but gave very low basal activity. Therefore, four $5^{\prime}$ flanking regions, -1131 to $-546 \mathrm{bp},-551$ to $+5 \mathrm{bp},-551$ to $-459 \mathrm{bp}$, and -547 to -516 bp of the human GnRH gene were placed upstream of the TK promoter fused to the CAT reporter gene (pTKCAT). These constructs were transfected into JEG-3 cells and CAT activity determined. We have previously demonstrated low levels of estrogen receptor (ER) mRNA by Northern blot analysis in JEG-3 cells (data not shown), but to augment ER levels, an expression vector containing the SV40 early promoter and the human estrogen receptor cDNA (pKCR2ER, gift of P. Chambon) was cotransfected in some experiments. Fig. $1 A$ shows that in the absence of cotransfected estrogen receptor $0.1 \mathrm{nM}$ or $10 \mathrm{nM}$ estradiol did not stimulate CAT activity from pTKCAT, p-1131/-546TKCAT, or p-551/+5TKCAT.

However, when $1 \mu \mathrm{g}$ of pKCR2ER was cotransfected, the constructs p-551/+5TKCAT, p-551/-459TKCAT, and p-547/ -516TKCAT but not p-1131/-546TKCAT or pTKCAT displayed a 2.4-, 2.2-, and 3.6-fold increase, respectively, in CAT activity when exposed to $10 \mathrm{nM}$ estradiol (Fig. $1 B$ ). Fig. $1 B$ also demonstrates a concentration dependence of this estrogen

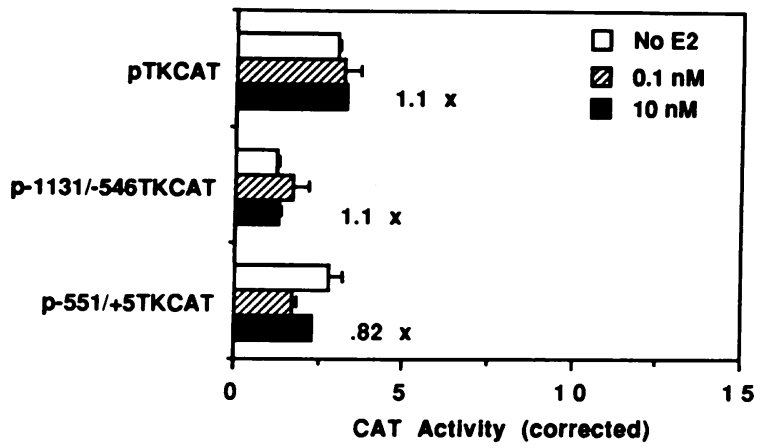

A

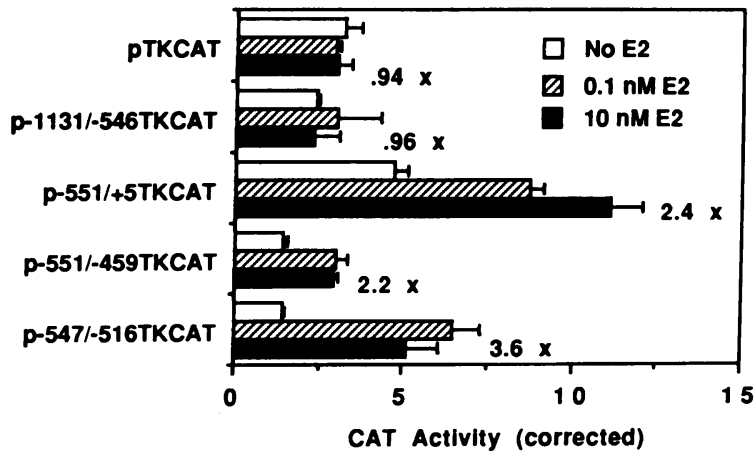

B

Figure 1. 5' flanking regions of the human GnRH gene were ligated upstream of the TK promoter in pTKCAT. The regions placed upstream of TK are indicated by the numbers that precede TKCAT. These constructs were transfected into JEG- 3 cells without $(A)$ or with a human ER-cDNA (pKCR2ER) expression vector $(B)$ and CAT activity was measured $48 \mathrm{~h}$ after either no treatment, or treatment with either 0.1 or $10 \mathrm{nM}$ estradiol (E2). CAT activity is expressed as percent acetylation in $16 \mathrm{~h} / \mathrm{mg}$ of protein.

effect over a range from 0.1 to $10 \mathrm{nM}$ estradiol for the $\mathrm{p}-551 /$ +5 TKCAT construct. These data indicate that, in the presence of cotransfected estrogen receptor, estrogen responsiveness could be conferred to the heterologous TK promoter in JEG-3 cells using DNA sequences located between -547 and -516 bp of the human GnRH gene.

To study estrogen regulation of the native promoter, we initially utilized only the $5^{\prime}$ flanking region of the gene $(-1131$ to $+5 \mathrm{bp}$ ) fused to the LUC gene, but again this construct displayed low basal LUC activity (Nakayama, Y., M. Yamada, G. B. Cutler Jr., B. Weintraub, S. Radovick, manuscript submitted for publication). Thus, we constructed several human GnRH-LUC expression vectors containing DNA sequences downstream from the transcription initiation site. pGnRH.3E contains -1131 to $+2684 \mathrm{bp}$ (end of the third exon) of GnRH; pGnRH.2E contains -1131 to $+1073 \mathrm{bp}$ (end of the second exon) of GnRH; and pGnRH.2E/-82 contains -82 to +1073 bp of GnRH. To prevent read-through translation from $\mathrm{GnRH}$ coding sequences, translational stop codons were introduced into each of these constructs in the appropriate reading frame. To control for nonspecific effects, a construct containing the Rous sarcoma virus promoter, pRSVL, was utilized. Fig. 2 


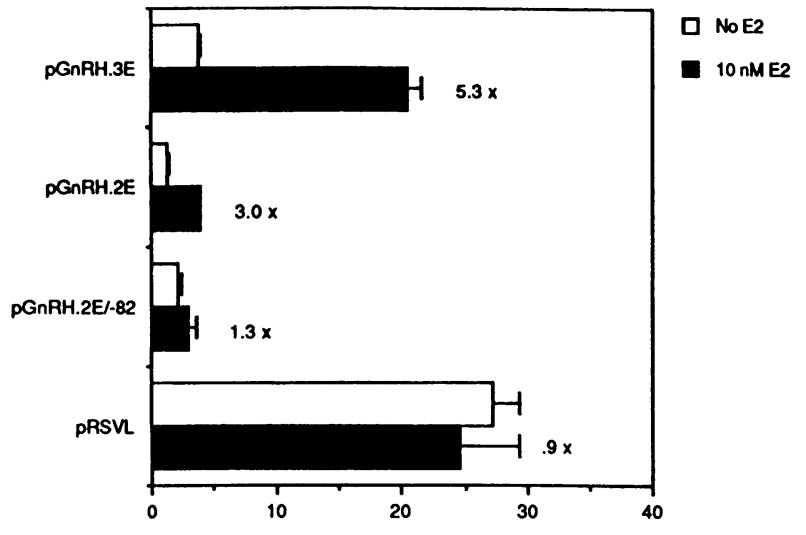

Relative Light Units (RLU $\times 10-3$, corrected)

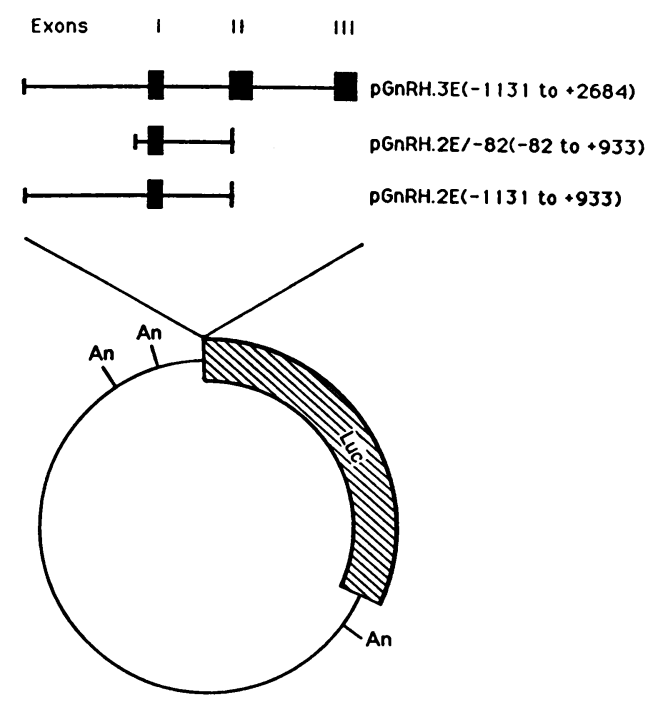

Figure 2. Human GnRH-LUC expression constructs were cotransfected into JEG-3 cells with pKCRER. Constructs are shown diagrammatically here and described in the text. Shown is the relative light unit production corrected for transfection efficiency from cell cultures receiving either no treatment or treatment with $10 \mathrm{nM}$ estradiol (E2). Activity of pRSVL (RSV) was determined from $0.1 \%$ of the cell lysate used for human GnRH construct determinations.

shows the results of an experiment done in JEG-3 cells with all constructs cotransfected with pRSVCAT (to correct for transfection efficiency) and pKCRER (to maximize the estradiol response).

Cell cultures transfected with pGnRH.2E and pGnRH.3E displayed a significant three- to fivefold increase in LUC activity upon treatment with estradiol $10 \mathrm{nM}(P<0.001)$. Since there was a reduction in estrogen responsiveness when the second intron and third exon were deleted (pGnRH.3E versus pGnRH.2E), we can not exclude that an additional ERE is located in this region. However, a $5^{\prime}$ deletion of pGnRH.2E, pGnRH.2E/-82, displayed no significant increase in activity. As expected, LUC activity from $p R S V L$ was unaltered by estradiol treatment. These results provide additional evidence that an ERE is located between -1131 and -82 bp of the human GnRH gene, and when combined with previous CAT data, this ERE can be localized to -547 to $-516 \mathrm{bp}$.

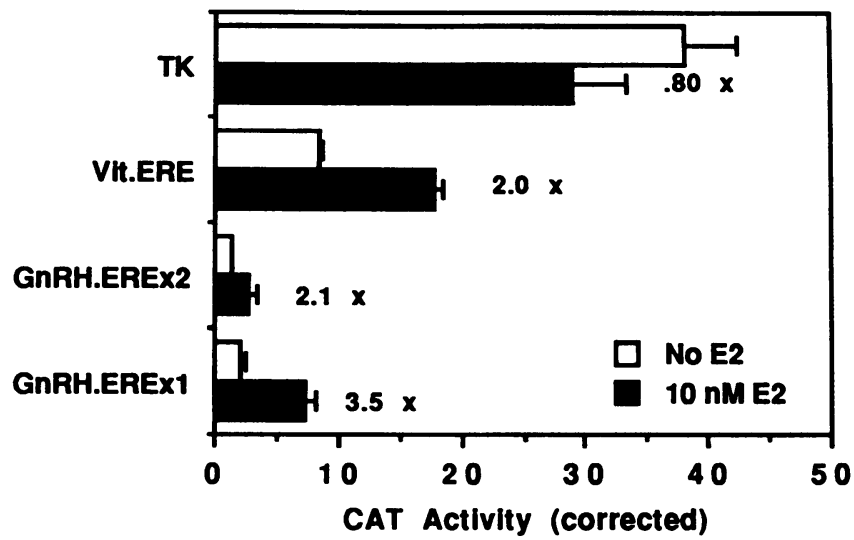

Figure 3. Estrogen response elements were ligated upstream of pTKCAT. The vitellogenin ERE, or one or two copies of the human GnRH ERE ( -547 to $-516 \mathrm{bp}$ ) was ligated upstream of the TK promoter in pTKCAT forming VIT.ERE, GnRH.EREx 1 , and GnRH.EREx2, respectively. These constructs were transfected into JEG-3 cells with a human ER-cDNA (pKCR2ER) expression vector, and CAT activity was measured $48 \mathrm{~h}$ after either no treatment or treatment with $10 \mathrm{nM}$ estradiol (E2). CAT activity is expressed as percent acetylation in $16 \mathrm{~h} / \mathrm{mg}$ of protein.

Comparison of the human GnRH and vitellogenin estrogen response elements. To compare the EREs in the human GnRH and vitellogenin gene, they were inserted upstream of the TK promoter in pTKCAT. Fig. 3 illustrates that in the presence of cotransfected estrogen receptor either one (GnRH.ERE $\times 1)$ or two $(\mathrm{GnRH}$.ERE $\times 2)$ copies of the human GnRH gene or the vitellogenin ERE (VIT.ERE) conferred estrogen responsiveness to the TK promoter. Thus, a human GnRH ERE located between -547 and $-516 \mathrm{bp}$ is necessary and sufficient to confer estrogen responsiveness to a heterologous promoter. Interestingly, each of the ERE constructs displayed a significant decrease in basal activity as compared with the parent construct. This was most notable for the human GnRH.ERE $\times 2$ construct and may explain why the estrogen induction was lower in this construct than in the human GnRH.ERE $\times 1$ construct. Moreover, the estrogen stimulatory responses may be somewhat lower than expected because, in this experiment, promoter activity from the parent construct, pTKCAT, was inhibited by estradiol treatment.

DNase I footprinting of the human GnRH gene using purified estrogen receptor. To determine whether estrogen receptor binds to the human GnRH gene, a DNA fragment from -611 to $-82 \mathrm{bp}$ was radiolabeled at the $5^{\prime}$ end, incubated with various concentrations of purified estrogen receptor derived from calf uterus, and partially digested with DNase I. Fig. 4 demonstrates that increasing concentrations of estrogen receptor from 0.17 to $17 \mathrm{nM}$ resulted in a strong footprint between -514 and $-567 \mathrm{bp}$ at $17 \mathrm{nM}$. These results are consistent with previous data from other investigators (25) who have determined that the $K_{\mathrm{d}}$ of estrogen receptor binding to estrogen response elements was 2-5 $\mathrm{nM}$. The footprinted region is somewhat larger than expected. This may be due to the pattern of DNase I digestion and the location of the radiolabel near the $5^{\prime}$ border of the footprint. Other investigators have also had difficulty establishing clear borders of estrogen receptor binding using a modification of the DNase I footprinting technique (26). 


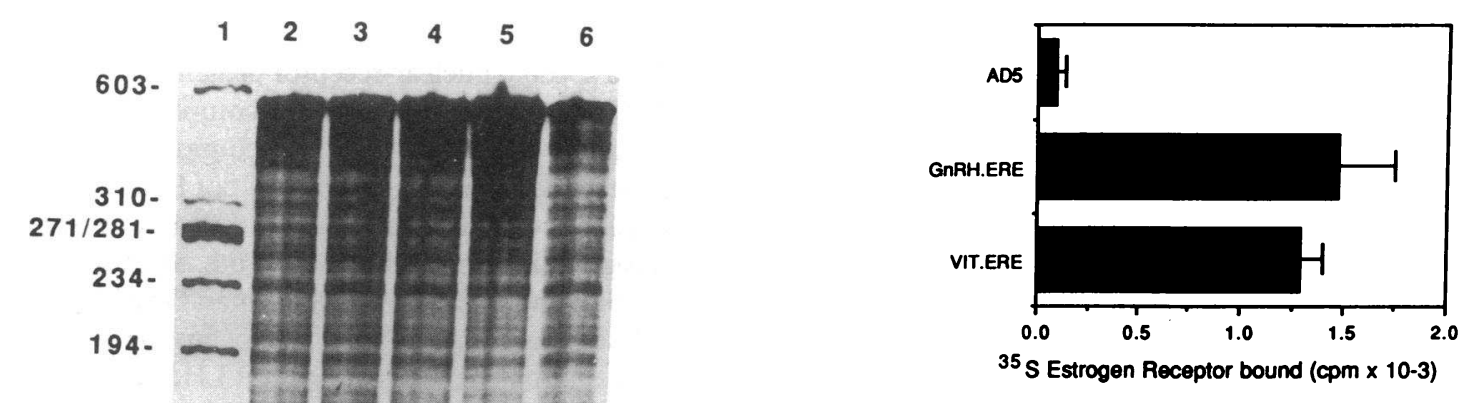

$-514$

$-567$

34.

Figure 4. DNase I footprinting of the human GnRH gene using purified estrogen receptor. A radiolabeled human $\mathrm{GnRH}$ probe $(-611$ to $-82 \mathrm{bp}$ ) was incubated with either no receptor (lanes 2 and 6 ), or $0.17,1.7$ or $17 \mathrm{nM}$ purified calf uterine estrogen receptor (lanes 3, 4 , and 5 , respectively) in $50 \mu \mathrm{l}$ of a buffer containing $50 \mathrm{mM} \mathrm{KCl}$, $10 \%$ glycerol, $20 \mathrm{mM}$ Tris pH $8.0,1 \mathrm{mM}$ DTT, $1 \mathrm{mM} \mathrm{MgCl} 2,1 \mathrm{mM}$ EDTA, $100 \mathrm{nM} 17-\beta$-estradiol, $100 \mu \mathrm{g} / \mathrm{ml} \mathrm{BSA}$, and $4 \mu \mathrm{g}$ of poly dI$\mathrm{dC}$ for $30 \mathrm{~min}$ at $25^{\circ} \mathrm{C}$. The binding reactions were partially digested with DNase I $\left(0.6 \mu \mathrm{g}, 2 \mathrm{~min}\right.$ at $\left.25^{\circ} \mathrm{C}\right)$ and separated on an $8 \%$ denaturating polyacrylamide gel. Lane $l$ contains a radiolabeled molecular weight marker.

Estrogen receptor binding to human GnRH gene utilizing the avidin-biotin DNA-binding assay. Therefore, we employed the avidin-biotin DNA-binding assay to confirm the results of estrogen receptor binding to sequences identified by DNase I footprinting. A biotinylated DNA fragment containing -551 to -512 bp of the human GnRH gene (GnRH.ERE) was utilized in the avidin-biotin DNA-binding assay. As a positive control, a well-defined ERE from the xenopus vitellogenin gene (VIT.ERE) was utilized; as a negative control we employed AD5, the same DNA fragment used by other investiga-
Figure 5. Estrogen receptor binding to human GnRH gene utilizing the avidinbiotin complex DNA-binding assay (ABCD assay). Double-stranded oligonucleotides from the long terminal repeat of AD5, the VIT.ERE, and the

human GnRH gene ( -551 to $-512 \mathrm{bp}$, GnRH.ERE) were synthesized with identical 5 ' overhangs and filled in with biotin-11 dUTP. Radiolabeled ( ${ }^{35} \mathrm{~S}$ methionine) human ER was prepared using an in vitro transcription-translation system. Each binding reaction contained $1 \mathrm{pm}$ of the respective biotinylated DNA fragment $(20 \mathrm{nM})$ and $1 \times 10^{-4} \mathrm{cpm}$ of ${ }^{35} \mathrm{~S}$-labeled human ER as determined by TCA precipitation.

tors (27) studying estrogen receptor binding to biotinylated DNA fragments in this assay. Fig. 5 demonstrates that both GnRH.ERE and VIT.ERE bound $\sim 15$-fold more ${ }^{35}$ S-labeled estrogen receptor than the negative control fragment, adenovirus $5,(\mathrm{AD} 5)$ at a DNA concentration of $20 \mathrm{nM}$. These results confirm that the estrogen receptor binds to the human $\mathrm{GnRH}$ gene, and localize the region of binding from -551 to $-514 \mathrm{bp}$.

To localize further the region to which the estrogen receptor interacts with the human GnRH gene, a series of adjacent biotinylated DNA fragment of the human GnRH gene was synthesized. Fig. 6 demonstrates that a region from -541 to $-517 \mathrm{bp}$ bound ${ }^{35} \mathrm{~S}$-labeled estrogen receptor to a similar extent as the vitellogenin ERE. However, the regions surrounding -541 to $-517 \mathrm{bp}$ did not bind significant amounts of the radiolabeled receptor.

To determine the affinity of estrogen-receptor binding to the GnRH.ERE and the vitellogenin ERE, the avidin-biotin DNA-binding assay was again employed with various concentrations of biotinylated DNA fragments. Fig. 7 demonstrates that both the GnRH ERE and the vitellogenin ERE bound the estrogen receptor with high affinity $\left(K_{\mathrm{d}} \sim 1 \mathrm{nM}\right)$, while the AD5 bound the estrogen receptor at considerably lower affinity.

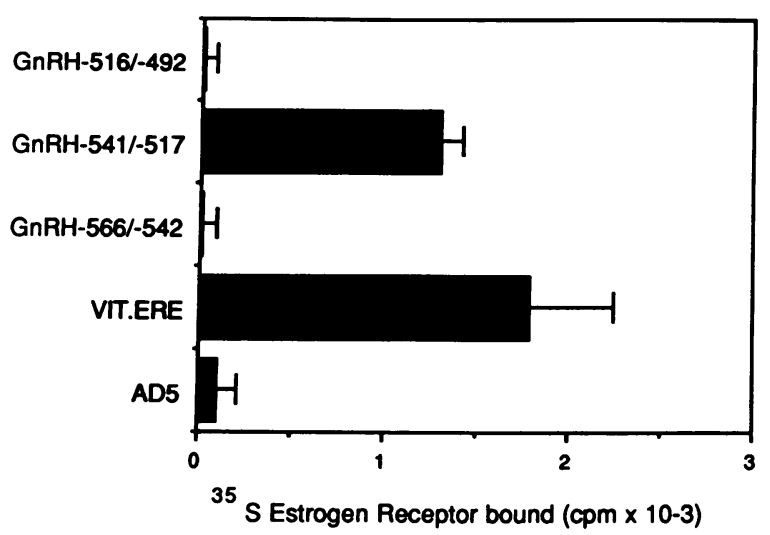

Figure 6. Further location of estrogen receptor binding in the human $\mathrm{GnRH}$ gene. The ABCD assay was employed using adjacent biotinylated DNA fragments of the human GnRH gene, the long terminal repeat of AD5, and the VIT.ERE, as described in the Fig. 5 legend. 


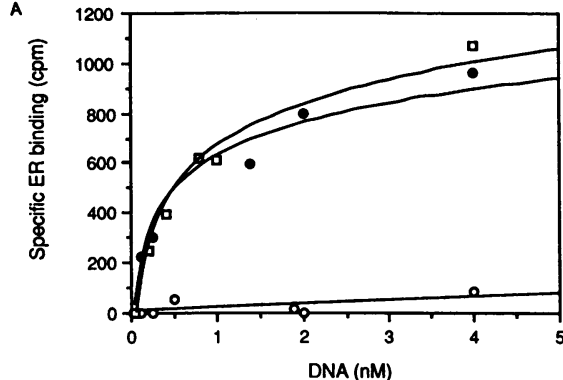

B

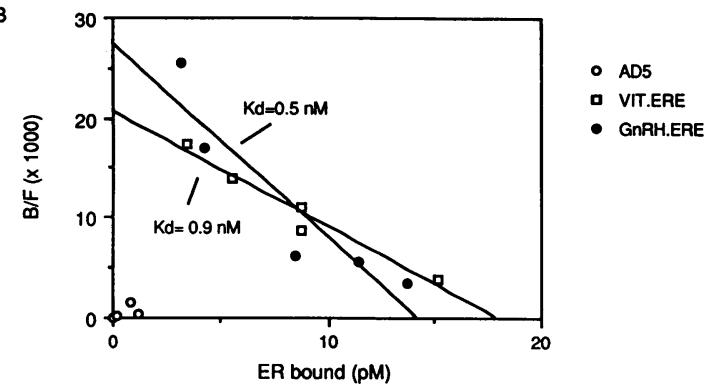

Figure 7. Affinity of estrogen receptor binding to the GnRH and vitellogenin ERE. The avidin-biotin DNA-binding assay was performed with various concentrations of biotinylated DNA fragments as described in the Fig. 5 legend. $(A)$ Specific estrogen receptor $(E R)$ binding in cpm versus the concentration of biotinylated DNA fragments is displayed. Data points are the mean of duplicate determinates from three separate experiments. $(B)$ Scatchard analysis of DNA binding was performed. The dissociation constants $\left(K_{d}\right)$ were calculated from the Scatchard plots.

\section{Discussion}

The molecular mechanisms of $\mathrm{GnRH}$ regulation by estrogen are largely unknown. For example, the effect of estrogen on GnRH mRNA levels is controversial as is whether estrogen acts directly on the GnRH neuron to regulate its expression. The GnRH neuron may be directly regulated by estrogen or
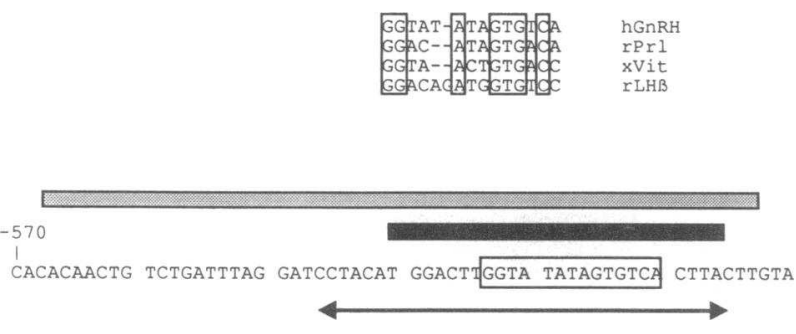

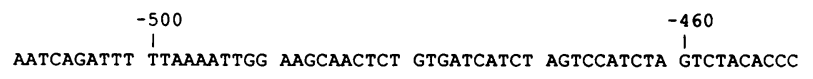

Figure 8. Summary of functional and structural assays used to determine an ERE in the human GnRH $5^{\prime}$ flanking region. Localization by functional assays (line with arrowheads) of estrogen responsiveness and structural assays, DNase I footprint (stippled box) and avidinbiotin DNA-binding assays (black stippled box), of estrogen receptor binding. At the top is the putative ERE sequence in the human GnRH gene, between -534 and -521 bp (boxed), compared with that of the EREs in the rat prolactin, xenopus vitellogenin, and rat LH $\beta$. indirectly regulated through contact with other neurons. Estrogen interacts with a specific nuclear-receptor protein and binds to distinct DNA regions as a steroid-receptor complex to influence gene transcription $(28,29)$. Although a consensus-pallindromic estrogen-response element (ERE) was not found upon sequencing the $1.2 \mathrm{~kb}$ of 5 -flanking GnRH DNA, one area with high homology to known EREs was found. As shown in Fig. 8, between -534 and -521 bp in the human GnRH gene (boxed) is a DNA sequence that is $80 \%$ homologous to EREs in the rat prolactin, xenopus vitellogenin, and rat $\mathrm{LH} \beta$ genes $(25$, $28,30)$.

Fig. 8 also demonstrates that both functional and structural assays used in this study localize a stimulatory ERE to this region of DNA sequence homology. Functional assays indicate that a stimulatory ERE is localized between -547 and -516 bp (line with arrowheads), while DNAse I footprinting (stippled box) and the avidin-biotin DNA-binding assay (black-stippled box) indicate that the estrogen-receptor binds to -567 to -514 bp and -541 to $-517 \mathrm{bp}$, respectively, of the human GnRH gene. These regions overlap between -541 and $-517 \mathrm{bp}$, which, as noted above, contains a DNA sequence homologous to other reported EREs between -534 and $-521 \mathrm{bp}$.

Comparisons among the EREs indicate that the EREs from the $\operatorname{rLH} \beta$ and hGnRH gene contain one- and two-bp insertions, respectively, between putative half-sites of estrogen-receptor binding (31). The relatively modest stimulatory response to estrogen (threefold) noted in the rLH $\beta$ and hGnRH genes, versus the dramatic stimulatory response noted in the vitellogenin gene, in some systems, may be due to differences in estrogen-receptor binding among these elements. Moreover, differences among EREs may have physiological importance where either a modest or dramatic stimulatory response to estrogen may be required to elicit the appropriate biological response. However, in the cotransfection system we utilized, we did not observe a significant difference in estrogen responsiveness among the EREs.

The data presented in this paper do not prove that estrogen directly regulates human GnRH expression in the hypothalamus. However, several lines of evidence strongly suggest a direct regulatory role for estrogen. For example, in an analogous system Petraglia et al. (32) showed that estrogen stimulated expression of immunoreactive $\mathrm{GnRH}$ approximately threefold from cultured human placental cells. Since the human placenta contains abundant estrogen receptors, this is consistent with the data we have presented. Moreover, Komm et al. (18) and Eriksen et al. (19) showed that as few as 200-500 estrogen receptors per nucleus in osteoblastlike cells were sufficient to mediate an induction of type I procollagen, transforming growth factor- $\beta$, and progesterone receptor in these cells. In addition, as few as 500 estrogen receptors per cell nucleus are sufficient to initiate ovalbumin transcription in the chicken oviduct (33). Thus, estrogen receptors sufficient to mediate a GnRH stimulatory response might not be detectable in hypothalamic GnRH neurons using in situ ligand (16) or antibodybinding assays (17). Finally, in most studies, at least some GnRH neurons do contain detectable estrogen receptors (16, 17). This leaves open the possibility that certain populations of GnRH neurons are directly regulated by estrogen while other neurons are either indirectly regulated or not regulated by estrogen. This is analogous to central regulation of the thyrotropin-releasing hormone neuron where only certain populations 
of thyrotropin-releasing hormone neurons are regulated by thyroid hormone (34).

In conclusion, we have shown that the human GnRH gene contains a functional ERE between -547 and $-516 \mathrm{bp}$. DNase I footprinting and the avidin-biotin complex DNA-binding assay demonstrate estrogen-receptor binding to -567 to -514 bp and -541 to $-517 \mathrm{bp}$, respectively, of the human GnRH gene. The presence of an ERE, defined by both functional and structural studies, suggests that human GnRH gene expression in the hypothalamus may be directly stimulated by estrogen, and that this stimulation might account for increased GnRH secretion observed at the time of the preovulatory LH surge.

\section{References}

1. Wray, S., P. Grant, and H. Gainer. 1989. Evidence that cells expressing luteinizing hormone-releasing hormone mRNA in the mouse are derived from progenitor cells in the olfactory placode. Proc. Natl. Acad. Sci. USA. 86:81328136.

2. Seeburg, P. H., A. J. Mason, T. A. Stewart, and K. Nikolics. 1987. The mammalian GnRH gene and its pivotal role in reproduction. Recent Prog. Horm. Res. 43:69-98.

3. Marshall, J. C., and R. P. Kelch. 1986. Gonadotropin-releasing hormone: role of pulsatile secretion in the regulation of reproduction. N. Engl. J. Med. 315:1459-1468.

4. Carmel, P. W., S. Araki, and M. Ferin. 1975. Pituitary stalk portal blood collection in rhesus monkeys: evidence for pulsatile release of gonadotropin-releasing hormone (GnRH). Endocrinology. 99:243-248.

5. Gross, D. S. 1980. Effect of castration and steroid replacement on immunoreactive gonadotropin-releasing hormone in the hypothalamus and preoptic area. Endocrinology. 106:1442-1450.

6. Rudenstein, R. S., H. Bigdeli, M. H. McDonald, and P. J. Snyder. 1979. Administration of gonadal steroids to the castrated male rat prevents a decrease in the release of gonadotropin-releasing hormone from the incubated hypothalamus. J. Clin. Invest. 63:262-267.

7. Reame, N., S. E. Sauder, R. P. Kelch, and J. C. Marshall. 1984. Pulsatile gonadotropin secretion during the human menstrual cycle: evidence for altered frequency of gonadotropin-releasing hormone secretion. J. Clin. Endocrinol. \& Metab. 59:328-337.

8. Pfaff, D. W. 1986. Gene expression in hypothalamic neurons: luteinizing hormone-releasing hormone. J. Neurosci. Res. 16:109-115.

9. Rothfield, J. M., J. F. Hejtmancik, P. M. Conn, and D. W. Pfaff. 1987 LHRH messenger RNA in neurons in the intact castrate male rat forebrain, studied by in situ hybridization. Exp. Brain Res. 67:113-118.

10. Roberts, J. L., C. M. Dutlow, M. Jakubowski, M. Blum, and R. P. Millar. 1989. Estradiol stimulates preoptic area-anterior hypothalamic pro-GnRH-GAP gene expression in ovariectomized rats. Mol. Brain Res. 6:127-134.

11. Rothfeld, J., J. F. Hejtmancik, P. M. Conn, and D. W. Pfaff. 1989. In situ hybridization for LHRH mRNA following estrogen treatment. Mol. Brain Res. 6:121-125.

12. Park, O., S. Gugneja, and K. E. Mayo. 1990. Gonadotropin-releasing hormone gene expression during the rat estrous cycle: effects of pentobarbital and ovarian steroids. Endocrinology. 127:365-372.

13. Zoeller, R. T., P. H. Seeburg, and W. S. Young III. 1988. In situ hybridization histochemistry for messenger ribonucleic acid (mRNA) encoding gonadotropin-releasing hormone (GnRH): effect of estrogen on cellular levels of GnRH mRNA in female rat brain. Endocrinology. 122:2570-2577.

14. Wray, S., R. T. Zoeller, and H. Gainer. 1989. Differential effects of estrogen on luteinizing hormone-releasing hormone gene expression in slice explant cultures prepared from specific rat forebrain regions. Mol. Endocrinol. 3:11971206.
15. Toranzo, D., E. Dupont, J. Simardt, C. Labrie, J. Couet, F. Labrie, and G. Pelletier. 1989. Regulation of pro-gonadotropin-releasing hormone gene expression by sex steroids in the brain of male and female rats. Mol. Endocrinol. 3:17481756.

16. Shivers, B. D., R. E. Harlan, J. I. Morrell, and D. W. Pfaff. 1983. Absence of oestradiol concentration in cell nuclei of LHRH-immunoreactive neurones. Nature (Lond.). 304:345-347.

17. Watson, R. E., M. C. Langub, and J. W. Landis. 1990. Further evidence that LHRH neurons are not directly estrogen responsive: LHRH and estrogen receptor immunoreactivity in the guinea pig brain. Neuroscience. 495.4 (Abstr)

18. Komm, B. S., C. M. Terpening, D. J. Benz, K. A. Graeme, A. Gallegos, M. Korc, G. L. Greene, B. W. O'Malley, and M. R. Haussler. 1988. Estrogen binding, receptor mRNA, and biologic response in osteoblast-like osteosarcoma cells. Science (Wash. DC). 241:81-84.

19. Eriksen, E. F., D. S. Colcard, N. J. Berg, M. L. Graham, K. G. Mann, T. C. Spelsberg, and B. L. Riggs. 1988. Evidence of estrogen receptors in normal human osteoblast-like cells. Science (Wash. DC). 304:84-86.

20. Sambrook, J., E. R. Fritsh, and T. Maniatis. 1989. Molecular Cloning: A Laboratory Manual. Cold Spring Harbor Laboratory, Cold Spring Harbor, NY.

21. Radovick, S., F. E. Wondisford, Y. Nakayama, M. Yamada, M. G. B. Cutler, Jr., and B. D. Weintraub. 1990. Isolation and characterization of the human gonadotropin-releasing hormone gene in the hypothalamus and placenta. Mol. Endocrinol. 4:476-480.

22. de Wet, J. R., K. Y. Wood, M. DeLuca, D. R. Helinski, and S. Subramani. 1987. Firefly luciferase gene: structure and expression in mammalian cells. Mol. Cell. Biol. 7:725-737.

23. Sanger, F., S. Nicklen, and A. R. Coulson. 1977. DNA sequencing with chain-terminating inhibitors. Proc. Natl. Acad. Sci. USA. 74:5463-5467.

24. Wondisford, F. E., E. A. Farr, S. Radovick, H. Steinfelder, J. M. Moates, J. H. McClaskey, and B. D. Weintraub. 1989. Thyroid hormone inhibition of human thyrotropin b-subunit gene expression is mediated by a cis-acting element located in the first exon. J. Biol. Chem. 264:14601-14604.

25. Maurer, R. A., and A. C. Notides. 1987. Identification of an estrogen-responsive element from the $5^{\prime}$ flanking region of the rat prolactin gene. Mol. Cell Biol. 7:4247-4254.

26. Cridland, N. A., C. V. E. Wright, E. A. McKenzie, and J. Knowland. 1990. Selective photochemical treatment of oestrogen receptor in a Xenopus liver extract destroys hormone binding and transcriptional activation but not DNA binding. EMBO (Eur. Mol. Biol. Organ.). 9:1859-1866.

27. Glass, C. K., J. M. Holloway, O. Y. Devary, and M. G. Rosenfeld. 1988. The thyroid hormone receptor binds with opposite transcriptional effects to a common sequence motif in thyroid hormone and estrogen response elements. Cell. 54:313-323.

28. Klein-Hitpass, L., M. Schorpp, U. Wagner, and G. U. Ryffel. 1986. An estrogen-responsive element derived from the $5^{\prime}$ flanking region of the xenopus vitellogenin A2 gene functions in transfected human cells. Cell. 46:1053-1061.

29. Waterman, M. L., S. Adler, C. Nelson, G. L. Greene, R. M. Evans, and M. G. Rosenfeld. 1988. A single domain of the estrogen receptor confers deoxyribonucleic acid binding and transcriptional activation of the rat prolactin gene. Mol. Endocrinol. 2:14-21.

30. Shupnik, M. A., C. M. N. Weinmann, A. C. Notides, and W. W. Chin. 1989. An upstream region of the rat-luteinizing hormone $\beta$ gene binds estrogen receptor and confers estrogen responsiveness. J. Biol. Chem. 264:80-86.

31. Kumar, V., and P. Chambon. 1988. The estrogen receptor binds tightly to its responsive element as a ligand-induced homodimer. Cell. 55:145-156.

32. Petraglia, F., J. Vaughn, and W. Vale. 1990. Steroid hormones modulate the release of immunoreactive gonadotropin-releasing hormone from cultured human placental cells. J. Clin. Endocrinol. \& Metab. 70:1173-1178.

33. Mulvihill, E. R., and R. D. Palmiter. 1977. Relationship of nuclear estrogen receptor levels to induction of ovalbumin and conalbumin mRNA in chick oviduct. J. Biol. Chem. 252:2060-2068.

34. Koller, K. J., R. S. Wolff, M. K. Warden, and R. T. Zoeller. 1987. Thyroid hormones regulate levels of thyrotropin-releasing hormone mRNA in the paraventricular nucleus. Proc. Natl. Acad. Sci. USA. 84:7329-7333. 